\title{
Orbital decompression in the system of treatment for complicated thyroid eye disease: case report and literature review
}

This article was published in the following Dove Press journal: International Medical Case Reports Journal

\author{
Dilyara S Ismailova' \\ Irina M Belovalova ${ }^{2}$ \\ Yaroslav O Grusha ${ }^{1,3}$ \\ Natalya Y Sviridenko ${ }^{2}$ \\ 'Research Institute of Eye Diseases, \\ Moscow, Russia; '2Endocrinology \\ Research Centre, Moscow, Russia; \\ ${ }^{3}$ I.M. Sechenov First Moscow State \\ Medical University, Moscow, Russia
}

Correspondence: Natalya Y Sviridenko Endocrinology Research Centre, II, Dmitriya Ulyanova Street, II 7036

Moscow, Russia

Tel +7499 I245832

Email natsvir@inbox.ru

\begin{abstract}
Orbital decompression is a surgical procedure aimed at increasing the orbital volume and/or decreasing the volume of the orbital fat. The indications for orbital decompression are determined in the course of thorough eye examination. An important objective of examination of a patient with thyroid eye disease (TED) is determination of inflammation activity and severity. Orbital decompression is a surgical procedure that can be performed in both the active and nonactive stages of the disease. However, the indications for the surgery in these cases are different. Optic neuropathy and severe corneal disease are threatening complications that may lead to permanent visual loss and generally occur in the presence of active orbital inflammation. If treatment with high-dose corticosteroids has proven ineffective, an urgent surgical procedure consisting of orbital decompression and, in case of involvement of the cornea, eyelid and corneal surgery has to be performed. Owing to significant progress in technology, improvement of methods and accumulated experience over the past decade, the indications for bone orbital decompression have extended compared to the time when this procedure was used only in patients with extremely severe TED. The most common complication of the orbital decompression is the development or deterioration of previously existing binocular diplopia and strabismus. In addition, other parameters may change as well, including the position of the globe, the eyelids, the angle of deviation of the eye, and intraocular pressure. Thus, bone orbital decompression is a major step of a comprehensive, often multistage, system of rehabilitation of patients with severe refractory TED.
\end{abstract}

Keywords: Graves' disease, thyroid eye disease, orbital decompression, ophthalmopathy, corneal ulcer, tarsoraphy

\section{Introduction}

Thyroid eye disease (TED) is the most common and quite often severe autoimmune disorder complicating the course of Graves' disease. In most cases (60\%), TED is not associated with serious eye disorders; however, even minimal cosmetic changes are sometimes poorly tolerated by patients. In approximately one-third of patients (mostly smokers), TED becomes severe and requires surgical treatment $(40 \%-45 \%)$ with the purpose of vision correction and correction of cosmetic defects. This may be due to delayed diagnosis of Graves' disease and TED itself, as well as untimely and inappropriate treatment.

Teamwork with patients is very important since therapy for TED requires strict maintenance of euthyroidism (normal levels of thyroid hormones). In addition to maintaining euthyroidism, other important factors related to TED treatment include decrease in duration and severity of active TED, prevention of fibrosis development, decrease 
in the frequencies of adverse effects, and complications of immunosuppressive therapy. The major personalized treatment criteria are the severity and activity of inflammation in the orbits ${ }^{1}$ since moderate and severe TED ${ }^{2}$ may be observed in patients with non-active disease, when immunosuppressive and radiation therapy are not effective. Optic neuropathy (ON) is a threatening complication of TED that develops in about $5 \%$ of patients and includes progressive visual loss, color vision impairment, visual field defects, and optic disc edema. ${ }^{3}$ In case of marked exophthalmos, lagophthalmos, lack of Bell's phenomenon, ophthalmoplegia, and subluxation of globe, a corneal ulceration and haze may occur. ${ }^{4}$ In these cases, treatment of active TED begins with immunosuppressive therapy with high-dose corticosteroids (CSs). High-dose methylprednisolone (pulse therapy) is recommended as a first-line therapy. ${ }^{5}$ If no improvement is observed within 2-3 weeks and the process in the orbits continues progressing, the only way to preserve vision is to perform an orbital decompression. ${ }^{6}$ The greatest difficulties are associated with treatment of patients with refractory TED complicated with ON with involvement of the cornea and marked hypotropia.

In Russia, treatment of severe TED is attended with great difficulties. There are several reasons for this. The first is connected with often inappropriate treatment of TED in nonspecialized clinics, which leads to delay in orbital surgery. The second reason is the orthodox opinion that bony orbital decompression carries a high risk of complications and has low effectiveness. And finally, access to specialized treatment in TED centers in faraway regions of Russia and monitoring of these patients is often difficult.

We present a clinical case of a female patient with severe TED and discuss the difficult choice of her personalized therapy.

\section{Case report}

Written informed consent was obtained from the patient to have the case details and images published.

A female patient aged 64 years presented to the Endocrinology research centre (Moscow, Russia) with complaints of continuous diplopia, bulging of both eyes, eye pain, eye redness, vision impairment, and color vision disturbances.

Eye pain, sensation of eye pressure, diplopia, and lacrimation manifested in June 2012.Thyrotoxicosis was diagnosed and therapy with antithyroid agents was initiated. The patient received the medications regularly and did not smoke. In September 2012, the patient received CS therapy (dexamethasone, 12 tablets per day followed by dose tapering), with insignificant improvement namely reduction of diplopia. Multiple periocular injections of CS were performed, resulting in insignificant positive changes.

In October 2013, the first pulse therapy with methylprednisolone $500 \mathrm{mg}$ IV (three injections) and oral dexamethasone was conducted, leading to short-term improvement. Starting from March 2014, methylprednisolone was administered according to the following regimens: $500 \mathrm{mg}$ IV No.3; 1000 mg IV No.3; $500 \mathrm{mg}$ No. 9; $250 \mathrm{mg}$ No. 9; $125 \mathrm{mg}$ No.9. Between methylprednisolone infusions, oral prednisone was administered. The patient reported short-term improvement and reduction in exophthalmos and diplopia. Overall cumulative dose of methylprednisolone comprised $15,170 \mathrm{mg}$ (>15 g), which is not currently considered an appropriate dosage. As a result of therapy, the patient's face became more round-shaped and she gained $7 \mathrm{~kg}$ of weight. Although pulse therapy with CS is better tolerated by patients compared to treatment with CS in tablets, approximately $0.8 \%$ of patients receiving high cumulative doses of CS develop acute liver disorder and fatal hepatic failure. The safe cumulative dose of methylprednisolone is $<8 \mathrm{~g}$.

Regarding the prior treatment, we should note that from the standpoint of evidence-based medicine, neither dexamethasone (because of its narrow therapeutic window) nor periocular injections of dexamethasone can be considered an optimal treatment option. Therefore, it is very disappointing that these regimens were used for a long time despite disease progression and the observed side effects.

On December 16, 2014, a thyroidectomy was performed at a local clinic and treatment with levothyroxine sodium 125 $\mu \mathrm{g}$ was prescribed. Histological examination demonstrated sclerosing follicular microcarcinoma. Thyroid scintigraphy was performed on January 22, 2015, and showed foci of weakly functioning tissue $(1.2 \times 1 \mathrm{~cm}$ on the right and $0.8 \times 0.8 \mathrm{~cm}$ on the left) in the bed of the removed thyroid gland. Blood tests were conducted on April 21, 2015, while the patient was receiving levothyroxine sodium $125 \mu \mathrm{g}$, and showed the following: thyroid-stimulating hormone $=0.57$ $\mathrm{mIU} / \mathrm{L}(0.23-4.2)$; free thyroxine $(\mathrm{fT} 4)=20 \mathrm{pmol} / \mathrm{L}(12-22)$; thyroglobulin $(\mathrm{Tg}) \leq 0.20 \mathrm{ng} / \mathrm{mL}$. No significant changes were observed in the eyes following surgical treatment. It should be noted that detection of microcarcinoma during thyroidectomy for Graves' disease is a well-known phenomenon, which does not significantly affect further treatment strategy. However, it can be a source of additional emotional burden for the patient. 
In April 2015, there was exophthalmos progression and eye pain. A corneal ulcer was discovered by a physician at a local clinic. Tarsorrhaphy was performed on the left eye.

On May 18, 2015, the patient was admitted to the Department of Therapeutic Endocrinology presenting with euthyroidism (thyroid-stimulating hormone $=1.26 \mathrm{mIU} / \mathrm{L}$; $\mathrm{Tg}=1.51 \mathrm{ng} / \mathrm{mL}$; anti-Tg antibodies $=13 \mathrm{IU} / \mathrm{mL}$; glucose $=5.0 \mathrm{mmol} / \mathrm{L}$ ). At the moment of admission, the patient was receiving levothyroxine sodium $125 \mu \mathrm{g}$.

Examination revealed bilateral marked exophthalmos, hyperpigmentation, and eyelid swelling. OD: dilated episcleral vessels, chemosis, and restriction of globe motility when looking upward and outward. Partial ankyloblepharon (result of tarsorrhaphy), lagophathalmos, hypotropia, and corneal ulcer were revealed (Figure 1). Multislice CT scan of the orbits revealed marked enlargement of extraocular muscles, apical crowding, swelling and fibrous changes in the orbital fat, and tightening optic nerves (Figure 2). Thyroid ultraso- nography showed the following measurements: total volume $=1.1 \mathrm{~cm}^{3}$, dimensions of the right lobe $=1.0 \times 1.0 \times 1.4 \mathrm{~cm}$, and dimensions of the left lobe $=0.9 \times 0.8 \times 1.3 \mathrm{~cm}$. The texture was heterogeneous, and echogenicity was decreased; color Doppler flow imaging showed moderately increased vascularization. Regional lymph nodes were up to $0.6 \mathrm{~cm}$ in diameter and of normal structure. Our conclusion after the subtotal thyroidectomy was that the echotexture of the residual thyroid tissue was typical of an autoimmune disorder.

Our diagnosis was primary hypothyroidism resulting from subtotal thyroidectomy for Graves' disease at the stage of drug-induced compensation, severe TED (active phase), optic neuropathy, binocular diplopia, and keratopathy. There was sclerosing microcarcinoma in the tissue of the removed thyroid gland.

It should be noted that although microcarcinoma is an accidental finding and no suppressive therapy with levothyroxine is required after its removal (and its detection

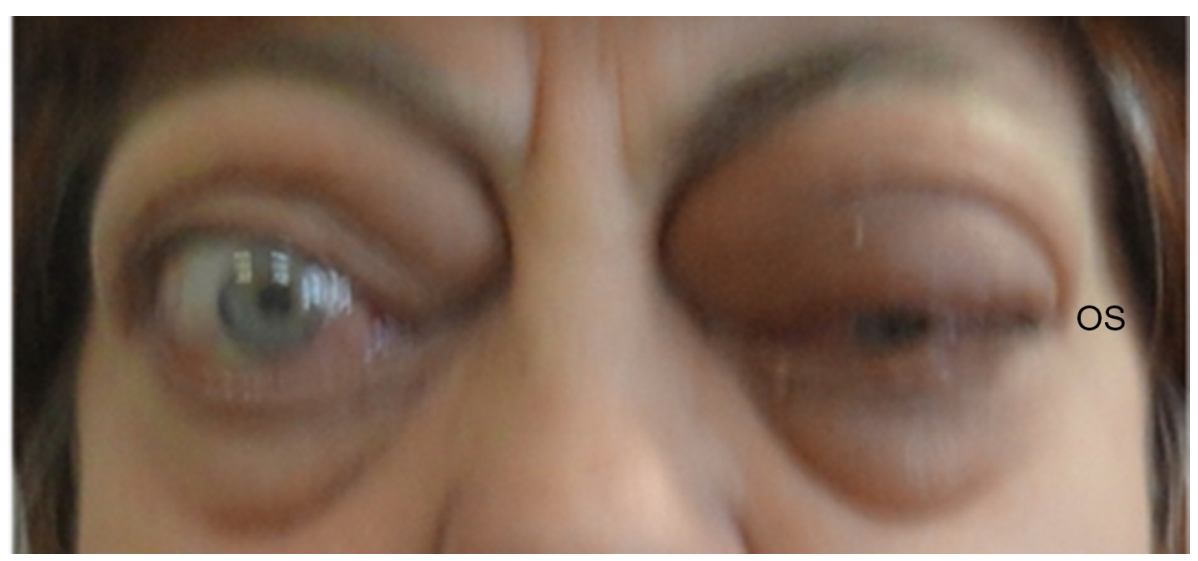

Figure I The patient's appearance on admission to Endocrinology research centre (Moscow, Russia).

Notes: OU (both eyes): exophthalmos; OS (left eye): interpalpebral adhesion, lagophthalmos, hypotropia, and corneal ulcer.

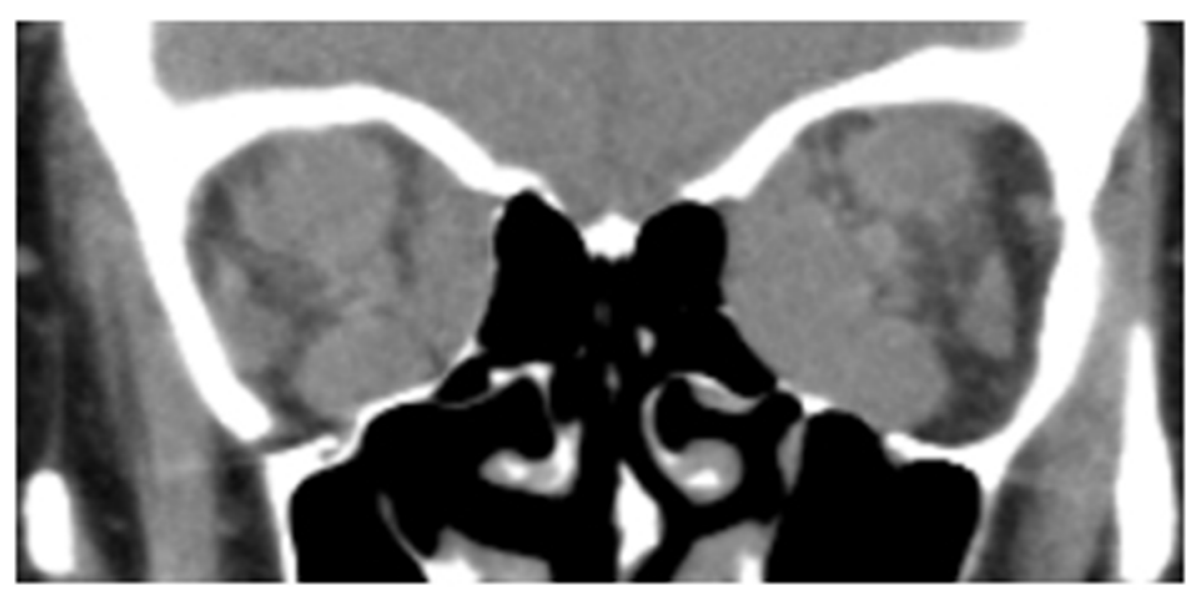

Figure 2 Multislice CT scan (coronal plane) prior to orbital decompression.

Note: There is significant enlargement of the extraocular muscles, more pronounced on the left, and apical crowding. 
does not affect the treatment strategy), subsequent thorough follow-up with control of the condition of lymph nodes and thyroglobulin levels may be needed because of the type of the tumor (sclerosing microcarcinoma).

Taking into account the lack of response to drug therapy, the presence of optic neuropathy, and the involvement of the cornea, the patient was referred to the Research Institute of Eye Diseases (Moscow, Russia) for orbital decompression.

At the moment of admission to the Institute of Eye Diseases, the OD visual acuity with the best correction (BCVA) was 1.0 and the OS was 0.2 . The OD IOP was $18 \mathrm{mmHg}$ and the OS IOP was $39 \mathrm{mmHg}$. There was marked bilateral eyelid swelling and bilateral exophthalmos. There was OD orthotropia; the movements were insignificantly restricted when looking upward. There was also retraction of the upper and lower eyelids but no lagophthalmos. Mild hyperemia and swelling of the conjunctiva were noted. The cornea had anterior stromal round opacities, most likely as a result of adenoviral conjunctivitis. The left palpebral fissure was partially closed in the outer half because of an interpalpebral adhesion (a result of tarsorrhaphy). The globe was deviated downward by $25^{\circ}$, with no movements above the level of primary gaze. Mild "red" chemosis and deep stromal opacity in the lower third of the cornea (outcome of the corneal ulcer) were seen. The lens showed initial cortical opacifications. The optic nerves on both sides were pale pink with well-defined borders.

On June 9, 2015, the bony decompression of three orbital walls of the left eye was performed. The lateral wall was resected via a transcutaneous approach; the medial and a part of the inferior wall were resected via a transconjunctival approach. However, due to lack of upward movements of the globe and poor Bell's phenomenon, temporary partial tarsorrhaphy was performed in order to prevent a recurrence of a corneal ulcer. At the moment of discharge from the hospital, the OS visual acuity was 0.4 and exophthalmos had decreased by $5 \mathrm{~mm}$, while the parameters of visual field examination and color perception improved and the intraocular pressure decreased to normal values. The findings of the multislice CT scan after the surgery are shown in Figure 3. The effect of the surgery remained stable for 1.5 months.

One-and-a-half months after OS decompression, the patient developed signs of reactivation of orbital inflammation. She received three IV injections of methylprednisolone $250 \mathrm{mg}$, which resulted in positive changes. Two-and-ahalf months after the decompression, a course of radiation therapy was conducted with a focal radiation therapy dose of $15 \mathrm{mSv}$ on each orbit. The treatment resulted in significant improvement.

Eight months after the end of radiation therapy, the patient underwent a surgical procedure for OS strabismus correction at a local clinic (Figure 4). Normalization of the eye position allowed to cut interpalpebral adhesion without a risk of a corneal ulcer recurrence (Figure 5). The patient also underwent cataract surgery (phacoemulsification) on both eyes at a local clinic, resulting in improvement of BCVA OD to 1.0, and OS to 0.9 . In this patient, a posterior capsular cataract was a complication of long-term therapy with corticosteroids as well as radiation therapy. There was no diplopia in primary gaze. While on therapy with antiglaucoma agents, IOP remained normal.

During a 2-year follow-up after the surgery, there were no new episodes of reactivation of the orbital inflammation,

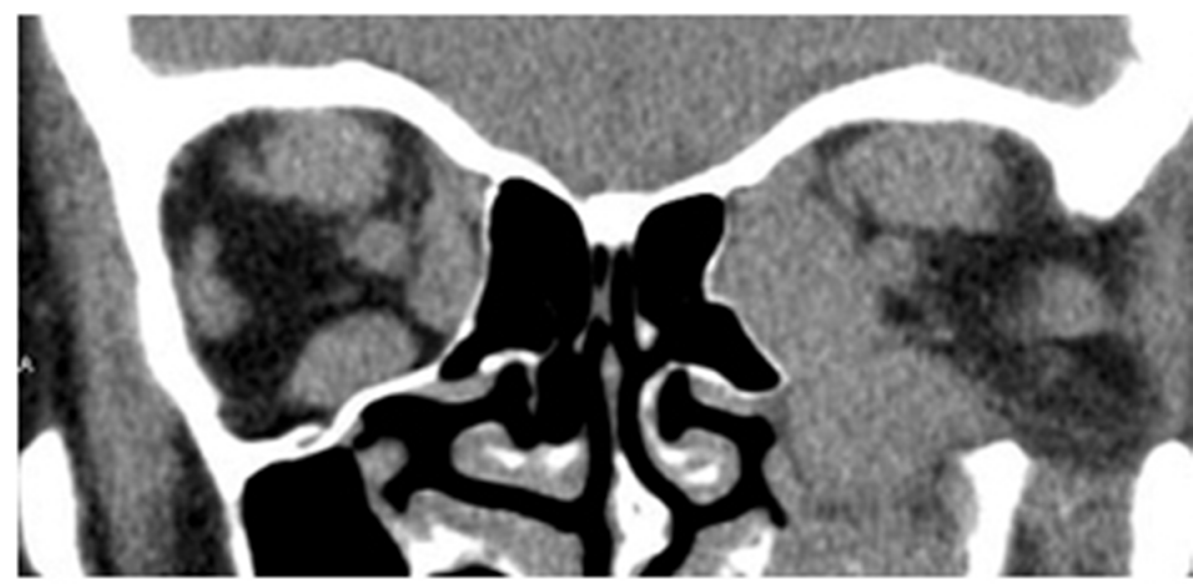

Figure 3 Multislice scan (coronal plane) I week after bony decompression of the left orbit.

Notes: There are defects in the lateral, medial, and inferior orbital walls. Significantly enlarged medial and inferior rectus muscles are displaced toward the defects in the corresponding walls. The lateral rectus muscle and orbital fat are observed outside the internal contour of the lateral wall. 


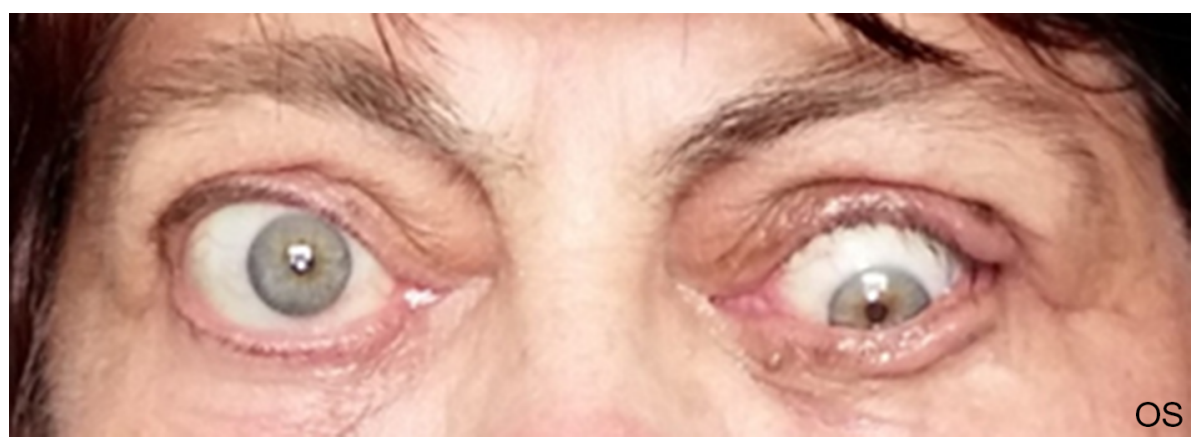

Figure 4 The patient's appearance 3 months after the orbital decompression and I month after the radiation therapy. Notes: OS (left eye): hypotropia, upper eyelid retraction, lagophthalmos, and superficial keratopathy.

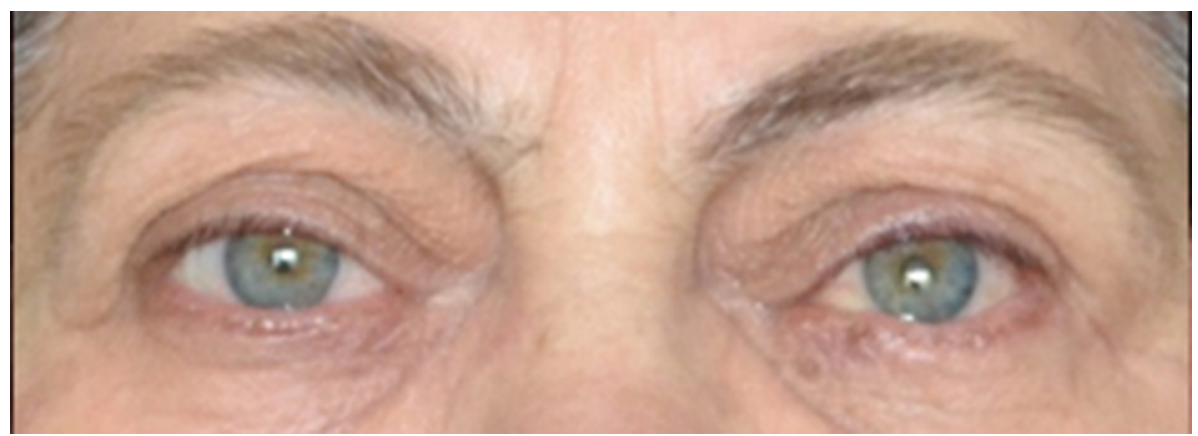

Figure 5 The patient's appearance 16 months after bony orbital decompression and strabismus surgery. Orthotropy in primary gaze position.

and no signs of exposure keratopathy or optic neuropathy. On replacement therapy with levothyroxine sodium $125 \mu \mathrm{g}$, the patient maintained stable euthyroidism.

\section{Discussion}

Corneal damage and $\mathrm{ON}$ are the most dangerous vision threatening complications of TED. In the case of delayed treatment, they can cause permanent visual loss. ${ }^{7}$ For patients with TED demonstrating no response to immunosuppressive therapy, bony orbital decompression is a key element of treatment and subsequent rehabilitation. ${ }^{8}$ Decompression surgery has been used for TED treatment for over 100 years. At first, it was only used in cases of severe complications, such as ON and keratopathy, which were refractory to drug therapy. Over the past several years, orbital decompression has been used in non-TED, with the purpose of eliminating cosmetic and functional defects. To date, many methods of decompression have been suggested in order to improve surgical outcomes and esthetic results, to decrease the duration of recovery period, to decrease the risk of iatrogenic complications, and specifically, to decrease the development of strabismus. ${ }^{9-15}$ The studies have shown that in most cases (except for rare cases when individual approaches were applied), the selection of a technique of surgical decompres- sion was based on clinical features, personal experience of a surgeon, and current treatment algorithms adopted in a particular country. Therefore, such parameters as reduction in the degree of exophthalmos, frequencies of complications and side effects, and the degree of patients' satisfaction were generally predictable and comparable. As has been demonstrated in clinical and experimental studies, decompression of two orbital walls leads to a decrease of approximately $3-6 \mathrm{~mm}$ in exophthalmos, which is why this procedure is most widely used. ${ }^{16-18}$ Removal of orbital fat results in an exophthalmos reduction of approximately $3-4 \mathrm{~mm} \cdot{ }^{19-22} \mathrm{In}$ some cases, the average exophthalmos reduction following the fat decompression is $5.3 \mathrm{~mm} .{ }^{23}$ Exophthalmos regression as a result of endonasal endoscopic orbital decompression via the transethmoidal approach is $3.5-6 \mathrm{~mm} .^{24,25}$ Improvement of the visual functions is observed in $82 \%$ of patients the next morning following the orbital decompression. The most common complications of this surgery include diplopia and strabismus, occurring in $15 \%-74 \%$ of patients. ${ }^{26-37}$ Ptosis and globe dystopia are far less frequent. Cases of some other rare complications such as cerebrospinal fluid leak, central nervous system infection, eye or optic nerve injury, cerebral vasospasm, traumatic neurinoma, trigeminal nerve damage, and intracranial hemorrhage have been reported. ${ }^{38-44}$ 
The methods of bony orbital decompression are constantly evolving. The preferred methods are combined ones: medial + inferior or balanced (medial + lateral). ${ }^{45} \mathrm{Up}$-to-date algorithms imply the use of bony orbital decompression followed by extraocular muscle surgery, correction of eyelid retraction, and esthetic eyelid and facial surgery. Each surgical procedure should be conducted while taking into account the needs of a particular patient and should aim not only to prevent blindness and restore the visual functions, but also for esthetic rehabilitation. This clinical case is of interest because of a severe course of refractory TED, which resulted in both corneal ulcer and ON. Using this case, we would like to demonstrate the necessity of a definite sequence of different treatment modalities and surgical interventions, in particular: immunosuppressive drug therapy, bony orbital decompression with tarsorrhaphy, radiation therapy during the active phase of the disease, and strabismus correction in fibrotic stage. In this case, the involvement of cornea in the active phase was caused by several factors, with the major role played by the enlargement of the inferior rectus muscle, secondary upward restriction, and, as a consequence, lack of Bell's phenomenon which, in the presence of lagophthalmos, led to corneal ulcer. At the same time, significantly enlarged extraocular muscles compressed the optic nerve at the apex of the orbit and caused the development of ON. Since TED was active, the pulse therapy was the first line of treatment. However, as a result of insufficient efficacy of prior therapy, bony orbital decompression was performed to "unload" the retrobulbar part of the orbit and tarsorrhaphy was performed to protect the cornea. ${ }^{46,47}$ The sequence used was quite unusual because the eyelid surgery was performed during the active phase; however, it was an urgent procedure because of corneal ulcer. In such a situation, this sequence was justifiable, as it allowed us to maintain the transparency of the optical zone of the cornea prior to the fibrotic stage when extraocular muscle surgery could be performed. Thus, bony orbital decompression is a major step of a comprehensive, often multistage system of rehabilitation of patients with severe refractory TED.

\section{Acknowledgment}

The authors acknowledge Dr Yury I Philippov for the help in formatting the manuscript and for submitting it to the journal.

\section{Author contributions}

NY Sviridenko and IM Belovalova (endocrinologists) supervised the patient. YO Grusha and DS Ismailova (ophthalmologists and surgeons) supervised the patient. All authors equally contributed to the case report data acquisition, and its analysis and interpretation. All authors substantially contributed to drafting, editing, and revising the article. They all read and approved the final version of the manuscript to be published and agree to be accountable for all aspects of the work in ensuring that questions related to the accuracy or integrity of any part of the work are appropriately investigated and resolved.

\section{Disclosure}

The authors report no conflicts of interest in this work.

\section{References}

1. Mourits MP, Koornneef L, Wiersinga WM, Prummel MF, Berghout A, van der Gaag R. Clinical criteria for the assessment of disease activity in Graves' ophthalmopathy: a novel approach. Br J Ophthalmol. 1989;73(8):639-644.

2. Werner SC. Modification of the classification of the eye changes of Graves' disease. Am J Ophthalmol. 1977;83(5):725-727.

3. Brovkina AF, Aubakirova AS. Zritel'nye rasstrojstva pri opticheskoj nejropatii u bol'nyh jendokrinnoj oftal'mopatiej [Visual disorders in optic neuropathy in patients with edematous exophthalmos]. In: Proceedings of the IX Conference, Aktual'nye voprosy nejrooftal'mologii. Moscow; 26 Jan 2007. P. 19-21.

4. European Group on Graves' Orbitopathy (EUGOGO), Wiersinga WM, Perros P, et al. Clinical assessment of patients with Graves' orbitopathy: the European Group on Graves' Orbitopathy recommendations to generalists, specialists and clinical researchers. Eur J Endocrinol. 2006;155(3):387-389.

5. Bartalena L, Baldeschi L, Boboridis K, et al. The 2016 European Thyroid Association/European Group on Graves' Orbitopathy Guidelines for the Management of Graves' Orbitopathy. Eur Thyroid J. 2016;5(1):9-26.

6. Krassas GE, Wiersinga WM. Thyroid eye disease: current concepts and the EUGOGO perspective. Thyroid International. 2005;4:3-21.

7. Sviridenko NY, Belovalova IM, Sheremeta MS. Graves'Ophthalmopathy. Moscow: MAI-PRINT; 2012.

8. Della Rocca RC. Thyroid-related orbitopathy: concepts and management. Facial Plast Surg. 2007;23(3):168-173.

9. Reich SS, Null RC, Timoney PJ, Sokol JA. Trends in Orbital Decompression Techniques of Surveyed American Society of Ophthalmic Plastic and Reconstructive Surgery Members. Ophthal Plast Reconstr Surg. 2016;32(6):434-437.

10. European Group on Graves' Orbitopathy (EUGOGO), Mourits MP, Bij1 $\mathrm{H}$, et al. Outcome of orbital decompression for disfiguring proptosis in patients with Graves' orbitopathy using various surgical procedures. $\mathrm{Br}$ J Ophthalmol. 2009;93(11):1518-1523.

11. Mehta P, Durrani OM. Outcome of deep lateral wall rim-sparing orbital decompression in thyroid-associated orbitopathy: a new technique and results of a case series. Orbit. 2011;30(6):265-268.

12. Sasim IV, de Graaf ME, Berendschot TT, Kalmann R, van Isterdael C, Mourits MP. Coronal or swinging eyelid decompression for patients with disfiguring proptosis in Graves' orbitopathy? Comparison of results in one center. Ophthalmology. 2005;112(7):1310-1315.

13. Baldeschi L, Macandie K, Hintschich C, Wakelkamp IM, Prummel MF, Wiersinga WM. The removal of the deep lateral wall in orbital decompression: its contribution to exophthalmos reduction and influence on consecutive diplopia. Am J Ophthalmol. 2005;140(4):642.e1-64642.

14. Bailey KL, Tower RN, Dailey RA, Customized DRA. Customized, single-incision, three-wall orbital decompression. Ophthalmic Plast Reconstr Surg. 2005;21(1):1-9.

15. Terwee CB, Gerding MN, Dekker FW, Prummel MF, Wiersinga WM. Development of a disease specific quality of life questionnaire for patients with Graves' ophthalmopathy: the GO-QOL. Br J Ophthalmol. 1998;82(7):773-779. 
16. Goldberg RA, Perry JD, Hortaleza V, Tong JT. Strabismus after balanced medial plus lateral wall versus lateral wall only orbital decompression for dysthyroid orbitopathy. Ophthalmic Plast Reconstr Surg. 2000;16(4):271-277.

17. Leone CR, Piest KL, Newman RJ. Medial and lateral wall decompression for thyroid ophthalmopathy. Am J Ophthalmol. 1989;108(2):160-166.

18. Mourits MP, Koornneef L, Wiersinga WM, Prummel MF, Berghout A, van der Gaag R. Orbital Decompression for Graves' Ophthalmopathy by Inferomedial, by Inferomedial Plus Lateral, and by Coronal Approach. Ophthalmology. 1990;97(5):636-641.

19. Prat MC, Braunstein AL, Dagi Glass LR, Kazim M. Orbital fat decompression for thyroid eye disease: retrospective case review and criteria for optimal case selection. Ophthalmic Plast Reconstr Surg. 2015;31(3):215-218

20. Trokel S, Kazim M, Moore S. Orbital fat removal. Decompression for Graves orbitopathy. Ophthalmology. 1993;100(5):674-682.

21. Kazim M, Trokel SL, Acaroglu G, Elliott A. Reversal of dysthyroid optic neuropathy following orbital fat decompression. Br JOphthalmol. 2000;84(6):600-605.

22. Richter DF, Stoff A, Olivari N. Transpalpebral decompression of endocrine ophthalmopathy by intraorbital fat removal (Olivari technique): experience and progression after more than 3000 operations over 20 years. Plast Reconstr Surg. 2007;120(1):109-123.

23. Brovkina AF. Endokrinnaja oftalmopatija [Endocrine ophthalmopathy]. Moscow: GEOTAR-Media; 2004.

24. Kochetkov PA, Sviridenko NY. Endonasal endoscopic transethmoidal orbital decompression for patients with Graves' desease and endocrine ophthalmopathy. Clinical and Experimental Thyroidology. 2010;6(1):26-31.

25. Kochetov PA, Lopatin AS, Sergienko NIu. Endonasal endoscopic orbital decompression through the transethmoidal approach. Vestn Otorinolaringol. 2009;4(4):23-26.

26. European Group on Graves' Orbitopathy (EUGOGO), Mourits MP, Bijl $\mathrm{H}$, et al. Outcome of orbital decompression for disfiguring proptosis in patients with Graves' orbitopathy using various surgical procedures. $\mathrm{Br}$ J Ophthalmol. 2009;93(11):1518-1523.

27. Metson R, Samaha M. Endoscopic orbital decompression. In: Woog JJ, editor. Manual of Endoscopic Lacrimal and Orbital Surgery. Vol. 1. Philadelphia, PA: Butterworth-Heinemann Medical; 2004.

28. Michel O, Oberländer N, Neugebauer P, Neugebauer A, Rüssmann W. Follow-up of transnasal orbital decompression in severe Graves' ophthalmopathy. Ophthalmology. 2001;108(2):400-404.

29. Metson R, Samaha M. Reduction of diplopia following endoscopic orbital decompression: the orbital sling technique. Laryngoscope. 2002;112(10):1753-1757.

30. Leone CR, Piest KL, Newman RJ. Medial and lateral wall decompression for thyroid ophthalmopathy. Am J Ophthalmol. 1989;108(2):160-166.

31. Mourits MP, Koornneef L, Wiersinga WM, Prummel MF, Berghout A, van der Gaag R. Orbital decompression for Graves' ophthalmopathy by inferomedial, by inferomedial plus lateral, and by coronal approach. Ophthalmology. 1990;97(5):636-641.
32. Rocchi R, Lenzi R, Marinò M, et al. Rehabilitative orbital decompression for Graves' orbitopathy: risk factors influencing the new onset of diplopia in primary gaze, outcome, and patients' satisfaction. Thyroid. 2012;22(11):1170-1175.

33. Ben Simon GJ, Syed HM, Syed AM, Lee S, et al. Strabismus after deep lateral wall orbital decompression in thyroid-related orbitopathy patients using automated hess screen. Ophthalmology. 2006;113(6): 1050-1055.

34. Esser J, Eckstein A. Ocular muscle and eyelid surgery in thyroidassociated orbitopathy. Exp Clin Endocrinol Diabetes. 1999;107(Suppl 5):S214-S221.

35. Fichter N, Schittkowski M, Hingst V, Guthoff RF. Graves' orbitopathy - radiological aspect safer orbital decompression and correlation to clinical findings. In: Proceedings of the 24th Meeting of the European Society of Ophthalmic Plastic and Reconstructive Surgery; 2006; London.

36. Esser J, Schittkowski M, Eckstein A. Graves' orbitopaty: inferior rectus tendon elongation for large vertical squint angles that cannot be corrected by simple muscle recession. Klin Monbl Augenheilkd. 2011;228(10):880-886.

37. Ruttum MS. Effect of prior orbital decompression on outcome of strabismus surgery in patients with thyroid ophthalmopathy. J Aapos. 2000;4(2):102-105.

38. Baldeschi L, Lupetti A, Vu P, Wakelkamp IM, Prummel MF, Wiersinga WM. Reactivation of Graves' orbitopathy after rehabilitative orbital decompression. Ophthalmology. 2007;114(7):1395-1402.

39. Anderson RL, Linberg JV. Transorbital approach to decompression in Graves' disease. Arch Ophthalmol. 1981;99(1):120-124.

40. Chang EL, Piva AP. Temporal fossa orbital decompression for treatment of disfiguring thyroid-related orbitopathy. Ophthalmology. 2008;115(9):1613-1619.

41. Bonavolontà G. Postoperative blindness following orbital surgery. Orbit. 2005;24(3):195-200.

42. Rose GE. The "devil's touch"; visual loss and orbital surgery. A synopsis of the Mustardé Lecture, 2006. Orbit. 2007;26(3):147-158.

43. Goldberg RA, Weinberg DA, Shorr N, Wirta D. Maximal, three-wall, orbital decompression through a coronal approach. Ophthalmic Surg Lasers. 1997;28(10):832-843.

44. Baldeschi L. Small versus coronal incision orbital decompression in Graves' orbitopathy. Orbit. 2010;29(4):177-182.

45. Reich SS, Null RC, Timoney PJ, Sokol JA. Trends in Orbital Decompression Techniques of Surveyed American Society of Ophthalmic Plastic and Reconstructive Surgery Members. Ophthalmic Plast Reconstr Surg. 2016;32(6):434-437.

46. Grusha YO, Ismailova DS, Gankovskaja OA. Risk factors damage to the cornea of patient with Graves' orbitopathy. Vestnik Oftalmologii. 2010;127(6):35-38.

47. Grusha YO, Ismailova DS, Sherstneva LV. Main principles of treatment the damage to the cornea of patient with Graves' orbitopathy. Vestnik Oftalmologii. 2015;132(5):35-38.
International Medical Case Reports Journal

\section{Publish your work in this journal}

The International Medical Case Reports Journal is an international, peer-reviewed open-access journal publishing original case reports from all medical specialties. Previously unpublished medical posters are also accepted relating to any area of clinical or preclinical science. Submissions should not normally exceed 2,000 words or
Dovepress

4 published pages including figures, diagrams and references. The manuscript management system is completely online and includes a very quick and fair peer-review system, which is all easy to use. Visit http://www.dovepress.com/testimonials.php to read real quotes from published authors. 